\title{
A Simultaneous Model and Empirical Test of the Demand and Supply of Retail Space
}

John D. Benjamin*

G. Donald Jud**

Daniel T Winkler $* * *$

\begin{abstract}
Much of the burgeoning distress of the 1990s in the United States retail space markets reflects a mismatch in the amount and location of retail space demand and supply. Understanding the demand and supply for retail space is critically important to academics, professionals and others associated with owning, operating and financing retail space. Using data from nineteen major metropolitan statistical areas (MSAs) for the period 1986-95, this article develops a simultaneous model of retail space demand and supply which includes the influence of vacancy rate. The model and results provide evidence about how demand and supply for retail space respond to changes in retail sales, rental prices, land-use regulation and land availability, and the cost of capital. The results show inelastic price elasticities of demand and supply for retail space.
\end{abstract}

Benjamin, J. D., G. D. Jud, and D. T. Winkler. "A Simultaneous Model and Empirical Test of the Demand and Supply of Retail Space," Journal of Real Estate Research, vol. 16, no. 1, 1998, pp. 1-13.

Made available courtesy of American Real Estate Society

\section{Introduction}

Much of the burgeoning distress of the 1990s in the United States retail space markets reflects a mismatch in the amount and location of retail space demand and supply. ${ }^{1}$ According to the International Council of Shopping Centers (ICSC) (1996a), shopping center space that captures about $70 \%$ of non-auto retail sales is being produced at a rate twice that of the U.S. population growth. Over the last decade, it has risen from 15.2 square feet per person in 1986 to 18.9 square feet per person as of January 1996 (a 24.3\% increase while the U.S. population grew only 10.3\%). ${ }^{2}$ Further, the excess supply of retail space or retail space saturation problem is compounded by stagnating or declining real retail sales. ${ }^{3}$ Pershio (1991), Wurtzebach (1993, 1995), Roulac (1994), Delisle, Grissom and Neyman (1995), Litt and van Dijkum (1995), Wheaton and Torto (1995) and other researchers have commented on the coming shakeout in retail space generated from an imbalance of the demand for space relative to changing supply both in the amount of retail space and its location. ${ }^{4}$ This mismatch in the demand and supply for retail space has the potential to reduce rents, raise vacancies and challenge the financial worthiness of retail landlords and creditors. ${ }^{5}$ Understanding

\footnotetext{
*Department of Finance and Real Estate, The American University, Washington, DC 20016 or jbenj@ american.edu.

**Department of Finance, University of North Carolina-Greensboro, Greensboro, NC 27412 or Juddon@ uncg.edu.

***Department of Finance, University of North Carolina-Greensboro, Greensboro, NC 27412 or winkler @iago.uncg.edu.
} 
the demand and supply for retail space is critically important to academics, professionals and others associated with owning, operating and financing retail space.

Although many academic studies have focused on the demand and supply elasticities for housing, few investigate the demand and supply of retail space. ${ }^{6}$ Given the relevance of market elasticity estimates to retail space investors and lenders, there exists a need to better understand the dynamics of retail space demand and supply. In this article, we present a simultaneous model of retail space demand and supply including the influence of vacancy rate. In section two, we analyze prior research on shopping center demand and supply. Section three presents a simultaneous model of the demand and supply for retail space. Section four describes the data and empirical model, and section five presents the empirical results. The implications of our findings are discussed in section six, while section seven provides a summary and conclusions.

\section{Demand and Supply for Retail Space}

Demand and supply fundamentals are some of the major determinants of investment returns to real estate. Many retail space market researchers, as earlier described, believe that the per capital supply of retail space is too great for the existing population demand. According to ICSC (1996b), extreme volatility has characterized the history of new retail supply. Changing rental rates, retail sales and other factors have influenced the demand for retail space while the economic climate, land availability, capital market cycles, interest rates and tax law changes have influenced the supply of new retail space. New retail space supply is also responsive to demographic, sociological, economic trends and local conditions. According to Ludgin, Perlmutter and Boss (1996), for example, the investment value of a specific retail center may be less dependent on national trends and more dependent on competition for retail sales from other local shopping centers. Factors affecting shopping center sales and profitability include: low retail vacancy, constraints on future development (e.g., zoning, few available sites, and master plan restrictions), population growth and aggregate disposable income of the local population.

Eppli and Shilling (1996) show that local retail competition and household income factors explain the local retail sales share for a particular mall. Using regression analysis and a data set of thirty-eight regional shopping malls, the authors demonstrate that retail sales at a local mall decrease based upon increased nearby competitive mall sizes, the distance to competition malls and lower aggregate household income.

A number of studies have focused on the economic and demographic determinants of demand and supply but have ignored the role of prices (i.e., rents). An extensive review of these studies can be found in Eppli and Benjamin (1994).

At any given moment, demand and supply for retail space may be moving toward or away from equilibrium. If demand decreases and supply increases, rents will fall and vacancies will rise. If demand increases or supply remains stable or decreases, rents will rise and vacancies will decrease. Given the long lead times necessary for retail 
space construction, retail demand and supply are usually not in equilibrium. Prior research confirms that retail space supply is slow to adjust to changing levels of retail sales. The lagged adjustment models employed by Benjamin, Jud and Okoruwa (1993), Benjamin, Jud and Winkler (1995) and Eppli and Shilling (1995) give empirical support to the argument that retail markets adjust very slowly to changes in the demand for retail space, as measured by the level of retail sales or the level of retail employment (also a proxy for retail sales). Local economic and demographic factors also impact retail sales for a particular market, but Benjamin, Jud and Okoruwa (1993) and Benjamin, Jud and Winkler (1995) show that economic and demographic factors are already captured in variables representing actual past retail sales. The long adjustment lags indicate a possible explanation for the prolonged cycles in retail space markets. These studies, however, are silent on the interaction of rents and vacancy because none of the models include price or rent variables together with vacancy rate in their analyses.

\section{A Simultaneous Model of Demand and Supply for Retail Space}

In order to tocus more closely on the role or prices and rents, we posit a simuitaneous demand and supply model for retail space that includes the influence of vacancy rate. The demand for space $\left(Q_{D}\right)$ is derived from the demand for retail goods and services. Demand is determined by the rental price $\left(P_{t}\right)$ of retail space and the level of retail sales $($ Sales $){ }^{7}$ Sales, in turn, are determined by relative prices, incomes and demographic factors. The supply of retail space $\left(Q_{S}\right)$ is influenced by the previous period's rental price of space $\left(P_{t-1}\right)$ and the relative cost of producing it (Cost). The rental price $\left(P_{t}\right)$ is related to the lagged rental price $\left(P_{t-1}\right)$ and the vacancy rate $(V R)$. These relations are expressed in the following model:

$$
\begin{aligned}
Q_{D} & =f\left(P_{t}, \text { Sales }\right), \\
Q_{S} & =f\left(P_{t-1}, \text { Cost }\right), \\
P_{t} & =f\left(P_{t-1}, V R\right), \\
V R & =1-Q_{D} / Q_{s}
\end{aligned}
$$

Prices, quantities and vacancy rates are endogenous; sales and cost variables are exogenous.

The cost variable of the supply equation includes capital costs and supply-side constraints. The cost of capital is measured by the real interest rate, that is, the interest rate on long-term government bonds less the inflation rate. The variation in land supply constraints across MSAs is measured by an index of land-use regulations and land availability.

The American Institute of Planners (AIP) (1976) developed an index of state landuse regulations that provides broad coverage and a rating of 0 (low regulation) to 8 (high regulation). Although this index is coded by state rather than MSA and dates 
to the late 1970s, it is still extensively employed to measure regulation. A study by Shilling, Sirmans and Guidry (1991), using the AIP index, reports that cities located in states with more restrictive land-use regulations have higher land prices.

Linneman, Summers, Brooks and Buist (1990) collected data on regulatory practices in a questionnaire about the development process in sixty large MSAs. Their resulting index, often referred to as the Wharton Index, has broad coverage and is relatively recent; however, it is more subjectively measured than the AIP index.

Another avenue of supply-side restraint is land availability. Segal and Srinivasan (1985) surveyed planning officials in fifty-one cities about the percentage of land removed from development by regulation; their index is an estimate of the percentage of undeveloped land by MSA. Malpezzi (1994) notes that the index is robust; although, some local responses appear inconsistent.

Rose (1989) developed a land supply index for forty MSAs of the percentage of land removed from development because of large bodies of water. The index ranges from 0 to 1.0; higher values (such as those cities with no water restrictions) indicate less restriction and potentially less limitation on development. Although the sample is limited in size and dependent upon an accurate estimate of the population density gradient (which he assumes to be the median value), the study shows that the land supply index based on water restrictions is important in explaining interurban land price differences.

All of the aforementioned measures of supply-side constraints appear to be related to measures of land regulation and availability. Moreover, regulation and availability are usually concurrent influences. The problem, however, is that many of these supplyside measures are constructed from additive measures or they are largely subjectively derived from survey data. Therefore, the meaning of the unit measurements is ambiguous, and it is necessary to construct an aggregate index to avoid the collinearity associated with simultaneously introducing all of these measures in a statistical (regression) model.

\section{Data and Estimation}

To estimate the simultaneous model of retail space demand and supply, we use data from nineteen metropolitan statistical areas (MSAs) for the years 1986-95. The final data set consists of 160 observations. ${ }^{8}$ The data for retail space and vacancy data, obtained by MSA from E W. Dodge, show the aggregate number of square feet of retail space (excluding restaurants). ${ }^{9}$ Aggregate real retail sales by year and MSA are obtained from Woods and Poole Economics, Inc., from data collected by the U.S. Department of Commerce. The mean effective monthly rental price per square foot of retail space is available from the National Real Estate Index's Market History Reports (1986-95) published by Koll Real Estate Services Company. These data are adjusted by the Consumer Price Index (CPI-U, 1982-84 = 100) to reflect constantdollar rents. Real interest rates on ten-year U.S. government bonds have been generated using the Citibank Data Set. 


\section{Exhibit 1 \\ Aggregate Index of Land-Use Regulation and Land Availability by Principal Component Analysis}

\begin{tabular}{lclc}
\hline Index Variable & Factor Loading & Factor Variance & Scoring Coefficient \\
\hline AlP & 0.7 & 0.5 & 0.3 \\
Wharton & 0.8 & 0.6 & 0.4 \\
Segal & 0.9 & 0.8 & 0.4 \\
Rose & -0.4 & 0.2 & -0.2 \\
Eigenvalue & & 2.0 & \\
Proportion of Total & & 0.5 & \\
Variance Explained & & & \\
\hline
\end{tabular}

Data sources: American Institute of Planners (1976), Segal and Srinivasan (1985), Rose (1989) and Linneman, Summers, Brooks and Buist (1990).

The regulatory cost indexes developed by the AIP and utilized by Shilling, Sirmans and Guidry (1991) along with the Wharton index are used to measure land-use regulations. The Segal and Srinivasan (1985) Index is employed as a measure of the percentage of land made unavailable by regulation. The Rose Index (1989) is used to gauge land availability in the presence of water restrictions. To avoid the collinearity problems of using multiple land-use regulation and land availability indexes, we create an aggregate measure of land-use regulation and land availability using the four indexes and the econometric method of principal components. In essence, this method reduces the number of regulatory variables to a smaller subset that contains most of the regulatory information from the full see. ${ }^{10}$

Exhibit 1 reports a factor analysis with principal components as the factor method. The eigenvalue of 2.042 (the sum of the squared factor loadings) suggests a strong common principal component for the four indexes. The proportion of total variance explained by one factor is approximately $51 \%$ (the eigenvalue divided by the number of indexes). All subsequent principal components (not reported in Exhibit 1) have eigenvalues less than 1.0 and explain less than $1 / p$ of the variation, where $p$ denotes the number of original variables. Therefore, only the first principal component is reported in Exhibit 1. The first column of Exhibit 1 shows the coefficients for the principal components. With the exception of the Rose Index, higher values of each index indicate greater regulation. Therefore, positive factor loadings for AIP and Wharton are consistent with more regulation. The Segal Index measures the percentage of land made unavailable for development by regulation; therefore, a positive factor loading is consistent with a loading measuring more regulation. The Rose Index measures land availability in the presence of bodies of water, with greater land availability having values closer to 1.0 while restricted MS As have values in the direction closer to 0 . The negative factor loading is consistent with the anticipated inverse relation between the Rose Index and regulation. The third column renders the scoring coefficients estimated by regression; the transformed data becomes the regulatory variable for the regression analysis. 
Estimates using these MSA data series provide a test of the validity of the simultaneous demand, supply, price and vacancy models shown in Equations (1)-(4).

The empirical model used to estimate the demand equation shown in Equation (1) is as follows:

$$
Q_{M, t}^{D}=D_{0}+D_{1} P_{M, t}+D_{2} S_{M, t}+D_{3} C D_{M}+e_{M, t}
$$

where $Q_{M, t}^{D}, P_{M, t}, S_{M, t}$ and $C D_{M}$, are the quantity of space demanded, the mean real effective monthly rental price of space (per square foot of retail space), real retail sales and regional (census) dummy variables-all continuous variables expressed as natural logarithms, respectively, for metro area $M$ in year $t$. The regression parameters are $D_{0}, D_{1}, D_{2}, D_{3}$ and the disturbance term is denoted by $e_{M, r}$.

Equation (2), representing the supply equation, is estimated for metro area $M$ in year $t$ using the following empirical model:

$$
Q_{M, t}^{S}=S_{0}+S_{1} P_{M, t-1}+S_{2} L R_{M}+S_{2} B D_{t}+S_{4} C D_{M}+z_{M, t},
$$

where:

$Q_{M, t}^{S}=$ The natural logarithm of quantity of space supplied;

$P_{M, t-1}=$ The natural logarithm of the mean real effective monthly rental price per square foot of retail space lagged one year;

$L R_{M}=$ The aggregate index of land-use regulation and land availability estimated by using principal components;

$B D_{t}=$ The natural logarithm of the real ten-year Treasury-bond yield;

$C D_{M}=$ The regional (census) dummy variables;

$S_{i}=$ The regression parameters (for $i=1,2,3$ or 4 ); and

$z_{M, t}=$ The disturbance term.

The empirical model used to estimate the rental price equation shown in Equation (3) which includes the vacancy rate in Equation (4) is as follows:

$$
P_{M, t}=R_{0}+R_{1} P_{M, t-1}+R_{2} V R_{M, t}+R_{3} C D_{M}+u_{M, t},
$$

where:

$P_{M, t}=$ The natural logarithm of the mean real effective monthly rental price of space (per square foot of retail space);

$P_{M, t-1}=$ The natural logarithm of the mean real effective monthly rental price per square foot of retail space lagged one year;

$V R_{M, t}=$ The natural logarithm of the vacancy rate $\left(1-Q_{, t} / Q_{,}\right)$;

$C D_{M}=$ The regional (census) dummy variables;

$R_{i}=$ The regression parameters (for $i=1,2$ or 3 ); and

$u_{M, t}=$ The disturbance term. 
In the following section, these simultaneous equations are estimated using the procedure of two-stage least squares (TSLS).

\section{Empirical Results}

Descriptive statistics for variables contained in the demand, supply and price equations as seen in Equations (5), (6) and (7) are shown in log form in Exhibit 2. For example, taking the anti-log of the mean real rental price indicates an average retail rental price of approximately $\$ 9.38$ per square foot in 1982-84 dollars. Similarly for 1986-95, the average real ten-year Treasury-bond yield is approximately $2.3 \%$.

The regression results for the estimated demand, supply and price equations are shown in Exhibit 3. ${ }^{11}$ Because the data are time series and cross-sectional, a regional census dummy variable is introduced into the regressions to capture the effects of variation specific to metropolitan areas. ${ }^{12}$ In addition, the set of estimated equations seen in Equations (5), (6) and (7) has an identification problem. Therefore, a three-stage generalized least squares procedure (TSGLS) is implemented. In the first stage, quantities and rental prices are regressed on the exogenous variables to establish the fitted values. The instruments include the CPI, year, credit, retail sales, lagged retail rent, the real ten year Treasury-bond rate and the aggregate index of land regulation and availability. In the second stage, the fitted values for supply quantities, demand quantities and rents are applied together with the other independent variables as shown in Equations (5), (6) and (7). The model with fitted values is first estimated ignoring

\section{Exhibit 2 \\ Descriptive Statistics for 19 MSAs from 1986-95 (expressed as natural logarithms)}

\begin{tabular}{lrrrr}
\hline Variable & Mean & \multicolumn{1}{c}{$\begin{array}{l}\text { Std. } \\
\text { Dev. }\end{array}$} & Max. & Min. \\
\hline Quantity Demanded $\left(O D_{M, t}\right)$ & 11.40 & 0.37 & 10.62 & 12.06 \\
Quantity Supplied $\left(O S_{M, t}\right)$ & 11.42 & 0.37 & 10.63 & 12.08 \\
Vacancy Rate $\left(V R_{M, t}\right)$ & 2.26 & 0.41 & 1.22 & 3.18 \\
Mean (Real) Effective Monthly Rent & 2.24 & 0.16 & 1.89 & 2.64 \\
per Square Foot $\left(P_{M, t}\right)$ & & & & \\
Mean (Real) Effective Monthly & 2.26 & 0.17 & 1.89 & 2.64 \\
Rent per Square Foot Lagged $\left(P_{M, t-1}\right)$ & & & & \\
Real Retail Sales $\left(S_{M, t}\right)$ & 9.63 & 0.40 & 8.78 & 10.45 \\
$\begin{array}{l}\text { Aggregate Index of Land Regulation } \\
\text { from Principal Components }\left(L R_{M, t}\right)\end{array}$ & $<-0.01$ & 1.01 & -1.27 & 2.39 \\
Real Ten-Year T-Bond Yield $\left(B D_{t}\right)$ & 0.85 & 0.35 & 0.28 & 1.82 \\
\hline
\end{tabular}

Note: $n=160$.

Data sources: F.W. Dodge, Woods and Poole Economics, Inc., National Real Estate Index's Market History Reports (1986-95) published by Koll Real Estate Services Company and Citibank Data Set. 


\section{Exhibit 3}

Three-Stage Regression Results

\begin{tabular}{lccc}
\hline Coefficient & Demand Equation & Supply Equation & Price Equation \\
\hline Constant & 3.44 & 10.58 & 0.49 \\
& $(29.39)$ & $(28.48)$ & $(37.38)$ \\
Real Retail Sales $\left(S_{M, t}\right)$ & 0.87 & & \\
& $(62.34)$ & & \\
Mean (Real) Effective Monthly Rent per & -0.20 & & \\
S.F. $\left(P_{M, t}\right)$ & $(-5.96)$ & & 0.88 \\
Mean (Real) Effective Monthly Rent per & & 0.49 & $(176.32)$ \\
S.F. Lagged $\left(P_{M, t-1}\right)$ & & $(2.84)$ & \\
Aggregate Index of Land Regulation from & & -0.12 & \\
Principal Components $\left(L R_{M, t}\right)$ & & $(-3.21)$ & \\
Natural Log of the Real Ten-Year T-Bond & & -0.03 & -0.10 \\
Yield (BD, & & $(-0.34)$ & $(-23.30)$ \\
Vacancy Rate $\left(V R_{M, t}\right)$ & & & 5,056 \\
F-Value & 964 & 16 & 0.99 \\
Adj. $R^{2}$ & 0.98 & 0.49 & 0.15 \\
Mean AR(1) & 0.15 & 0.15 & \\
\hline
\end{tabular}

Note: The regression results do not report the regional census dummy variables that are present to avoid a specification problem. An F-test of the full and reduced regression specification (without regional census variables) indicates the regional dummies are statistically significant at the .01 level. There are $n=160$ observations.

the autocorrelation in order to obtain a consistent estimate of $\rho$ for each MSA. In the third step, the $\rho$ estimates are applied to the data set using a Cochrane-Orcutt transformation; in this transformation, $z_{i t}=Z_{i t}-\rho Z_{i, t-1}$ where $Z_{i t}$ and $Z_{i, t-1}$ are the dependent and independent variables (Greene, 1993). The results reported in Exhibit 3 are the application of the transformed data to Equations (5), (6) and (7) including respective regional census dummies. ${ }^{13}$

The demand regression shown in Exhibit 3 is statistically significant at the .01 level, and the regression has an adjusted $R^{2}$ exceeding $98 \%$. The coefficient estimates for the retail sales and rental price coefficients possess the correct theoretical signs and statistical significance at the .01 level. The rental price coefficient of -0.2 shows that a $1 \%$ change in the rental price results in a $-0.2 \%$ change in demand for retail space. Therefore, the demand for retail space is highly inelastic with respect to rental price changes.

The estimated demand model also suggests that retail sales are very important in shaping the demand for retail space. The retail sales coefficient of 0.87 is a little less than 1.0 , indicating that a $1 \%$ change in sales creates approximately a $0.87 \%$ change 
in retail space demand. The retail sales coefficient of near unity supports the earlier findings of Benjamin, Jud and Okoruwa (1993) and Benjamin, Jud and Winkler (1995) who show that retail sales influence the quantity of retail space.

The second column in Exhibit 3 reports the results of the supply equation regression. The regression equation is statistically significant at the .01 level. Our findings confirm that retail space supply responds to variations in price and land regulation/availability. The rental price coefficient of 0.49 indicates that the supply of retail space is inelastic with respect to price. ${ }^{14}$ The land regulation/availability index coefficient is negative, revealing that more restrictive land-use regulations restrict the supply of retail space. The cost of capital coefficient is anticipated to be negative, as higher interest rates should reduce retail space availability. The bond rate coefficient, however, is not statistically significant. The real interest rate appears to have a minimal influence on the supply of retail space during this time period.

The third column of Exhibit 2 shows the results of the price equation regression. Almost all of the variation in rental prices is explained by the two included variables: the mean real rental price is directly associated with the previous rental price. Holding constant the monthly rent, a $1 \%$ increase in the vacancy rate decreases the rental price by $0.1 \%$; rental prices, therefore, are inelastic with respect to changes in vacancy.

\section{Implications}

The implications for structural changes in supply and demand for retail space including the problem of over-storing are examined in more detail by means of simulation analysis. Using the estimated coefficient values shown in Exhibit 3 and the mean values of the variables from Exhibit 2, we show the separate effects of $10 \%$ autonomous increases in demand and supply in Exhibit 4.

As shown from data from the nineteen MSAs contained within our sample, a $10 \%$ increase in demand initially results in an increase in rent $(+5.6 \%)$ and a large drop in the existing vacancy rate $(-48.0 \%)$. In subsequent periods (additional years) as supply begins to rise, the increase in rent slows and the vacancy rate rises. The system stabilizes after ten periods with higher rent and a lower vacancy rate and with larger quantities of shopping space demanded and supplied. An increase in supply of $10 \%$ leads to an initial fall in rent and an increase in the vacancy rate. As demand rises in response to lower rent, the pace of the decline in rent slows and the vacancy rate falls. In the end, the system stabilizes with rent lower and the vacancy rate higher along with both quantity demanded and supplied higher.

This sensitivity analysis clearly identifies the risks to shopping center developers. Developers who respond to positive demand shifts by building new shopping space should recognize that additional market supply following the increase in demand will slow the increase in rents and raise vacancy rates. Likewise on the supply side, moderate supply shifts decrease rents and raise vacancy rates as a result of the relative price inelasticity of shopping space demand. 


\begin{tabular}{lcccr}
\hline \multicolumn{5}{c}{$\begin{array}{c}\text { Exhibit 4 } \\
\text { Simulation Results }\end{array}$} \\
\hline Period & $\begin{array}{l}\text { Quantity } \\
\text { Demanded (\%) }\end{array}$ & $\begin{array}{l}\text { Quantity } \\
\text { Supplied (\%) }\end{array}$ & Rent (\%) & $\begin{array}{r}\text { Vacancy } \\
\text { Rate (\%) }\end{array}$ \\
\hline Panel A: $10 \%$ Increase in Demand & & & \\
\hline 1 & 7.3 & 0.0 & 5.6 & -48.0 \\
2 & -0.8 & 2.5 & 2.0 & 25.3 \\
3 & -0.4 & 0.9 & 0.9 & 8.0 \\
4 & -0.2 & 0.4 & 0.4 & 3.3 \\
5 & -0.1 & 0.2 & 0.2 & 1.5 \\
Total Change & 5.8 & 4.1 & 9.3 & -8.7 \\
\hline Panel B: $10 \%$ Increase in Supply & & & \\
\hline 1 & 1.6 & 9.5 & -3.8 & 32.8 \\
2 & 0.9 & -1.7 & -2.3 & -9.5 \\
3 & 0.5 & -1.0 & -1.3 & -6.2 \\
4 & 0.3 & -0.6 & -0.7 & -3.8 \\
5 & 0.2 & -0.3 & -0.4 & -2.2 \\
Total Change & 3.7 & 5.5 & -9.1 & 8.7 \\
\hline
\end{tabular}

\section{Summary and Conclusions}

In this article, we develop a simultaneous model of retail space demand and supply that includes vacancy rate. To estimate the model, we employ MSA data from twenty metropolitan markets for the period 1986-95. Our empirical results reveal inelastic price demand and supply elasticities for retail space. Because demand and supply are price inelastic, shifts in demand (supply) are found to result in relatively large changes in rent and relatively small changes in quantity demanded (supplied). Rental prices are largely explained by the previous year's rental price and the current year's vacancy rate, with higher vacancy rates resulting in lower rental prices.

In addition to the effects of price, we find that the demand for space is strongly influenced by the real level of retail spending; in particular, space demand seems to rise slightly less than in proportion to increases in real retail sales. On the supply side, the supply of space is negatively affected by more stringent land-use regulation and less land availability, while capital costs, as measured by interest rates, do not appear to have a significant impact on supply. 


\section{Appendix \\ Pearson Correlation Coefficient Matrix \\ (Probability in Parentheses)}

\begin{tabular}{lcccccc}
\hline & SALES & RETRENT & LRETRENT & RBOND & FACTOR1 & RETVR \\
\hline SALES & 1.000 & 0.249 & 0.226 & 0.034 & -0.268 & -0.112 \\
& $(0.0)$ & $(0.002)$ & $(0.004)$ & $(0.666)$ & $(<0.001)$ & $(0.159)$ \\
RETRENT & 0.249 & 1.000 & 0.963 & 0.091 & 0.375 & -0.200 \\
& $(0.002)$ & $(0.0)$ & $(<0.001)$ & $(0.255)$ & $(<0.001)$ & $(0.011)$ \\
LRETRENT & 0.226 & 0.963 & 1.000 & -0.002 & 0.357 & -0.119 \\
& $(0.004)$ & $(<0.001)$ & $(0.0)$ & $(0.975)$ & $(<0.001)$ & $(0.134)$ \\
RBOND & 0.034 & 0.091 & -0.002 & 1.000 & 0.002 & -0.138 \\
& $(0.666)$ & $(0.255)$ & $(0.975)$ & $(0.0)$ & $(0.984)$ & $(0.082)$ \\
FACTOR1 & -0.268 & 0.375 & 0.357 & 0.002 & 1.000 & -0.298 \\
& $(0.001)$ & $(<0.001)$ & $(<0.001)$ & $(0.984)$ & $(0.0)$ & $(<0.001)$ \\
RETVR & -0.112 & -0.200 & -0.119 & -0.138 & -0.298 & 1.000 \\
& $(0.159)$ & $(0.011)$ & $(0.134)$ & $(0.082)$ & $(<0.001)$ & $(0.0)$ \\
\hline
\end{tabular}

\section{Notes}

1. Casey (1996), Ludgin, Perlmutter and Boss (1996) and many others report on the widespread weakness in the retail space sector. Similarities exist between the retail space glut of the 1990s and the office space glut of the 1980s when office space supply exceeded demand. Recent bankruptcies among regional mall specialty stores such as Merry Go Round, Petrie Stores and Discovery Zone have raised the risks of retail investing. Ludgin et al. (1996) note that capitalization rates for retail properties have increased by 100 to 150 basis points during 1996 to reflect the growing uncertainty associated with investments in retail real estate. These authors note write-downs in mall values of 5\%-15\% due to the higher cap rates associated with greater perceived risk.

2. Additionally, those per capita supply amounts apply only to shopping center space and exclude free-standing big box space such as that from the rapidly expanding Wal-Mart and Target chains. Casey (1996) reports that the amount of free-standing store space constructed on a yearly basis doubled between the 1980s and the 1990s to 79 million square feet annually. Delisle, Grissom and Neyman (1995) comment that much of the big box retail space expansion is in the form of properties that are self-financed by retailers who seek market share at the expense of individual store profitability.

3. Wheaton and Torto (1995) document long-term declines in inflation-adjusted retail sales per square foot and inflation adjusted sales per retail worker. They also state that the growth of retail sales has been about half the construction rate for all retail space and only about a quarter of the construction rate for shopping center space. Further, the U.S. Bureau of the Census' Annual Retail Trade Survey and the National Research Bureau show the growth in sales of shopping centers to have been less than that of total retail sales. Total retail trade increased $6.3 \%$ in 1993 and $7.5 \%$ in 1994, while shopping center sales have only increased $5 \%$ in 1993 and 5.5\% in 1994. Casey (1996) reports that sales per square foot growth in regional shopping centers has been a sluggish 2.1\% in 1993, 1.8\% in 1994 and $0.5 \%$ in 1995.

4. Slowing occupancy rates for retail space hide the fact that growing demand based on increasing retail sales exists for retail space, but not in the amount of retail supply that is being created. Casey (1996) comments that new retail space represents a net addition to supply because much of the outmoded retail space reappears as recycled retail space in the hands of new owners. 
The potential additional repricing of retail property values reflects the increasing risks associated with the mismatch between retail demand and supply.

5 The possibility that non-store retailing such as direct marketing and electronic retailing will erode traditional retail sales is a growing threat. Electronic shopping methods include on-line retailing through the World Wide Web or through an online service provider, television shopping and CD-Rom retailing. Consumers may bypass traditional store retailers when electronic retailing gains widespread acceptance. Although electronic retailing is still in its infancy, Wheaton (1996) and Miller (1996) comment that electronic retailing including Internet retail sales could displace substantial retail space. Miller further comments (p. 21), "We have yet to see the electronic market unleashed, and when we do, the retail market share could easily exceed double the current estimate of $12 \%$ of all retail sales. Electronic retailing may take a generation to mature, but there is no doubt that it can go far beyond the limits of direct mail."

6 For a review of multi-family housing studies in this area, see Jud, Benjamin and Sirmans (1996).

7 Lagged retail sales are not included in the demand equation, but because of the lagged effect of prices and vacancy rate, any change in retail sales produces a lagged effect on price, quantity and vacancy rate. See the next section.

8 Rental price data spanned 1986-95 for eleven MSAs, 1988-95 for one MSA and 1990-95 for seven MSAs.

9 F. W. Dodge has been collecting square footage data since 1967 for use by the construction trades and others. Information concerning what is being built and where it is being built is reported.

10 Principle component analysis is used to explain the variance-covariance data structure through a lesser number of linear combinations of the original variables. The principal components replace the original variables (see, Johnson and Wichern, 1982). 11

11 The Pearson correlation coefficient matrix presented in the Appendix shows no substantial multicollinearity among the independent variables in the demand, supply and price equations.

12 A fixed effects model with MSA groups would typically be appropriate for the empirical regressions; however, regression coefficients are collinear in this specification. The aggregate index of land regulation and availability estimated from principal components possesses a unique value for each MSA. Therefore, a MSA fixed effects specification with the land regulation/availability variable leads to substantial regressor collinearity. An alternative specification is to use regional census dummy variables to control for variation associated with specific MSAs, which minimizes collinearity problems while capturing most of the variation associated with the MSA group variables. In addition, the real bond rate variable controls for most of the time variation.

13 Autocorrelation is removed by MSA because census regions usually have multiple MSAs. To remove autocorrelation, each cross-sectional unit must show consecutive and unique data points for the time series. The regional census variables are included in the regression equations to allow for separate intercepts for each region. The results reported with the transformed data are homoskedastic.

14 Supply is relatively non-responsive to changes in current prices.

\section{References}

American Institute of Planners, Survey of State Land Use Planning Activity, U.S. Department of Housing and Urban Development: Washington, DC, January 29, 1976.

Benjamin, J. D., G. D. Jud and A. Okoruwa, Forecasting the Stock of Retail Space Using the Koyck Distributed Lag Model, Journal of Property Research, 1993, 10, 185-92.

Benjamin, J. D., G. D. Jud, and D. T. Winkler, An Analysis of Shopping Center Investment, Journal of Real Estate Finance and Economics, 1995, 10:2, 161.68. 
Casey, D. M., Overstoring: A Look at Retail Space and Sales Performance, International Council of Shopping Centers White Paper, Edited by D. M. Kutyla, Fall, 1996.

Delise, J. R., T. V. Grissom and K. N. Neyman, Real Estate Outlook 1995, Atlanta: Equitable Real Estate Investment Management, 1995.

Eppli, M. J. and J. D. Benjamin, The Evolution of Shopping Center Research: A Review and Analysis, Journal of Real Estate Research, 1994, 9:1, 5-32.

Eppli, M. J. and J. D. Shilling, Speed of Adjustment in Commercial Real Estate Markets, Southern Economic Journal, 1995, 61:4, 1127-45.

- , How Critical is a Good Location to a Regional Shopping Center? Working paper, Madison, WI: University of Wisconsin-Madison, 1996.

Greene, W. H. Econometric Analysis, second edition, New York: Macmillan Publishing Co., 1993.

International Council of Shopping Centers, The Shopping Center Industry: A Look at the Last 10 Years, ICSC Research Quarterly, Summer 1996a, 3:2, 1-4.

International Council of Shopping Centers, Retail Construction: Has the Mix Really Changed? ICSC Research Quarterly, Spring 1996b, 3:1, 12-16.

Johnson, R. A. and D. W. Wichern, Applied Multivariate Statistical Analysis, Englewood Cliffs, NJ: Prentice-Hall, 1982.

Jud, G. D., J. D. Benjamin and S. G. Sirmans, What Do We Know About Apartments and Their Markets? Journal of Real Estate Research, 1996, 11:3, 243-58.

Linneman, P., A. Summers, N. Brooks and H. Buist, The State of Local Growth Management, Working Paper No. 81, Wharton Real Estate Center: Philadelphia, PA, November 1990.

Litt, J. and F. van Dijkum, The Salomon Brothers Commercial Real Estate Monitor, New York: Salomon Brothers, 1995.

Ludgin, M. K., R. D. Perlmutter and J. L. Boss, Softness in the U.S. Retail Market: Challenges and Opportunities, The Corridor Real Estate Journal, May 24-30, 1996, A15-17.

Malpezzi, S., Housing Prices, Externalities, and Regulation in U.S. Metropolitan Areas, University of Wisconsin Working Paper, Madison, WI: University of Wisconsin-Madison, 1994. Miller, N. G., Telecommunications Technology and Real Estate: Some Additional Perspectives, 1996, 13:2, 18-23.

National Research Bureau/Shopping Centers Today 1995 Shopping Center Census in Shopping Centers Today (April 1996), 21-31.

Pershio, D. B., The Coming Shakeout Among Regional Malls, JMB Perspectives, 1991, 1, 3 5.

Rose, L. A., Urban Land Supply: Natural and Contrived Restrictions, Journal of Urban Economics, 1989, 25:3, 325-45.

Roulac, S. E., Retail Real Estate in the 21st Century: Information Technology + Time Consciousness + Unintelligent Stores = Intelligent Shopping? Not! Journal of Real Estate Research, 1994, 9:1, 125-50.

Segal, D. and P. Srinivasan, The Impact of Suburban Growth Restrictions on U.S. Housing Price Inflation, 1975-78, Urban Geography, 1985, 6:1, 14-26.

Shilling, J. D., C. F. Sirmans and K. A. Guidry, The Impact of State Land-Use Controls on Residential Land Values, Journal of Regional Science, 1991, 31:1, 83-92.

U.S. Department of Commerce, Bureau of Census, State and Metropolitan Area Data Book, 1986.

Wheaton, W. C., A Perspective on Telecommunications Technology and Real Estate: Office, Industrial, and Retail Markets, Real Estate Finance, 1996, 13:2, 13-7.

Wheaton, W. C. and R. G. Torto, Retail Sales and Retail Real Estate, Real Estate Finance, $1995,5,22-31$. 